NASA/TM-2002-211337

AIAA-2001-1054

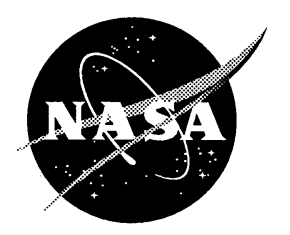

\title{
Simulated Space Vacuum Ultraviolet (VUV) Exposure Testing for Polymer Films
}

Joyce A. Dever

Glenn Research Center, Cleveland, Ohio

Anthony J. Pietromica

Ohio Aerospace Institute, Brook Park, Ohio

Thomas J. Stueber and Edward A. Sechkar

Dynacs Engineering Company, Inc., Cleveland, Ohio

Russell K. Messer

Cleveland State University, Cleveland, Ohio 
Since its founding, NASA has been dedicated to the advancement of aeronautics and space science. The NASA Scientific and Technical Information (STI) Program Office plays a key part in helping NASA maintain this important role.

The NASA STI Program Office is operated by Langley Research Center, the Lead Center for NASA's scientific and technical information. The NASA STI Program Office provides access to the NASA STI Database, the largest collection of aeronautical and space science STI in the world. The Program Office is also NASA's institutional mechanism for disseminating the results of its research and development activities. These results are published by NASA in the NASA STI Report Series, which includes the following report types:

- TECHNICAL PUBLICATION. Reports of completed research or a major significant phase of research that present the results of NASA programs and include extensive data or theoretical analysis. Includes compilations of significant scientific and technical data and information deemed to be of continuing reference value. NASA's counterpart of peerreviewed formal professional papers but has less stringent limitations on manuscript length and extent of graphic presentations.

- TECHNICAL MEMORANDUM. Scientific and technical findings that are preliminary or of specialized interest, e.g., quick release reports, working papers, and bibliographies that contain minimal annotation. Does not contain extensive analysis.

- CONTRACTOR REPORT. Scientific and technical findings by NASA-sponsored contractors and grantees.
- CONFERENCE PUBLICATION. Collected papers from scientific and technical conferences, symposia, seminars, or other meetings sponsored or cosponsored by NASA.

- SPECIAL PUBLICATION. Scientific, technical, or historical information from NASA programs, projects, and missions, often concerned with subjects having substantial public interest.

- TECHNICAL TRANSLATION. Englishlanguage translations of foreign scientific and technical material pertinent to NASA's mission.

Specialized services that complement the STI Program Office's diverse offerings include creating custom thesauri, building customized data bases, organizing and publishing research results ... even providing videos.

For more information about the NASA STI Program Office, see the following:

- Access the NASA STI Program Home Page at http://www.sti.nasa.gov

- E-mail your question via the Internet to help@sti.nasa.gov

- Fax your question to the NASA Access Help Desk at 301-621-0134

- Telephone the NASA Access Help Desk at 301-621-0390

- Write to:

NASA Access Help Desk

NASA Center for AeroSpace Information 7121 Standard Drive

Hanover, MD 21076 
NASA/TM-2002-211337

\section{Simulated Space Vacuum Ultraviolet (VUV) Exposure Testing for Polymer Films}

Joyce A. Dever

Glenn Research Center, Cleveland, Ohio

Anthony J. Pietromica

Ohio Aerospace Institute, Brook Park, Ohio

Thomas J. Stueber and Edward A. Sechkar

Dynacs Engineering Company, Inc., Cleveland, Ohio

Russell K. Messer

Cleveland State University, Cleveland, Ohio

Prepared for the

39th Aerospace Sciences Meeting and Exhibit

sponsored by the American Institute of Aeronautics and Astronautics

Reno, Nevada, January 8-11, 2001

National Aeronautics and

Space Administration

Glenn Research Center 


\section{Acknowledgments}

The authors gratefully acknowledge J. Mervin Bridges and Terrell Moore of the National Institute of Standards and Technology for conducting calibrations of deuterium lamps and obtaining transmittance spectra for Teflon FEP.

Trade names or manufacturers' names are used in this report for identification only. This usage does not constitute an official endorsement, either expressed or implied, by the National Aeronautics and Space Administration.

Available from

NASA Center for Aerospace Information 7121 Standard Drive

National Technical Information Service Hanover, MD 21076 


\title{
SIMULATED SPACE VACUUM ULTRAVIOLET (VUV) EXPOSURE TESTING FOR POLYMER FILMS
}

\author{
Joyce A. Dever \\ National Aeronautics and Space Administration \\ Glenn Research Center \\ Cleveland, Ohio 44135 \\ Anthony J. Pietromica \\ Ohio Aerospace Institute \\ Brook Park, Ohio 44142 \\ Thomas J. Stueber and Edward A. Sechkar \\ Dynacs Engineering Co., Inc. \\ Cleveland, Ohio 44135 \\ Russell K. Messer \\ Cleveland State University \\ Cleveland, Ohio 44115
}

\begin{abstract}
Vacuum ultraviolet (VUV) radiation of wavelengths between 115 and $200 \mathrm{~nm}$ produced by the sun in the space environment can cause degradation to polymer films producing changes in optical, mechanical, and chemical properties. These effects are particularly important for thin polymer films being considered for ultra-lightweight space structures, because, for most polymers, VUV radiation is absorbed in a thin surface layer. NASA Glenn Research Center has developed facilities and methods for long-term ground testing of polymer films to evaluate space environmental VUV radiation effects. VUV exposure can also be used as part of sequential simulated space environmental exposures to determine combined damaging effects. This paper will describe the effects of VUV on polymer films and the necessity for ground testing. Testing practices used at Glenn Research Center for VUV exposure testing will be described including characterization of the VUV radiation source used, calibration procedures traceable to the National Institute of Standards and Technology (NIST), and testing techniques for VUV exposure of polymer surfaces.
\end{abstract}

\section{Introduction}

Polymer films are often used for spacecraft thermal control as many possess the necessary optical properties (solar absorptance and thermal emittance), flexibility, and ease of fabrication and installation. However, polymer materials can experience degradation in optical and mechanical properties when exposed to the space environment for long periods of time. ${ }^{1,2}$ Damaging space environmental effects include solar ultraviolet radiation, solar flare $\mathrm{x}$-rays, electron and proton radiation, atomic oxygen for low Earth orbit missions, and temperature effects. Teflon FEP (fluorinated ethylene propylene), a common thermal control material, has been observed to become brittle upon long-term space exposure as observed on the Hubble Space Telescope (HST). ${ }^{2}$ Degradation of FEP on HST was found to increase with increasing dose of electrons, protons, ultraviolet and $\mathrm{x}$-ray radiation along with thermal cycling. ${ }^{2}$ While the typical polymer film thickness for thermal control materials ranges between 50 and $127 \mu \mathrm{m}$, trends continue toward use of large ultra-lightweight, inflatable or deployable structures requiring space-facing thin polymer films of $25 \mu \mathrm{m}$ or less such as the sunshield proposed for use on the Next Generation Space Telescope. $^{3} \quad$ These large area ultra-lightweight components will rely on the structural integrity of polymer films that are much thinner than have typically been used in the past for thermal control. Thinner materials will be more susceptible to radiation damage such as that provided by electrons, vacuum ultraviolet (VUV), and soft $x$ rays, because these radiation species can deposit significantly more energy in the polymer surface and deposited energy diminishes through the bulk of the material. ${ }^{4,5}$ For thinner polymers, a larger fraction of the bulk thickness would then be 
affected by deposited radiation. Some very large proposed spacecraft components, such as sunshields and inflatable structures, will require the thin polymer to be seamed, folded, and durable to stresses imposed by the deployed configuration. $^{3}$ These demands pose a number challenges in the area of space environmentally durable polymer films.

In order to qualify new polymers, and even thinner versions of commonly used polymers, for longterm space use, all aspects of the space environment must be considered. These environmental exposure factors include solar ultraviolet radiation, solar flare $\mathrm{x}$-ray radiation, electron and proton trapped particle radiation, operational temperatures or orbital temperature cycles, and atomic oxygen for the case of low Earth orbit missions. While the ideal test would simulate all effects to the same level of acceleration in the same facility, it is not possible to perfectly replicate all aspects of the space environment in this way. Sequential testing is often used where it is not convenient or possible to produce simultaneous effects in the same facility. Also, exposure to single environmental conditions is useful for screening, and for determining the role of individual environments in causing polymer film performance degradation. Exposure to simulated solar ultraviolet radiation in the vacuum ultraviolet (VUV) portion of the spectrum has been conducted at NASA Glenn Research Center to determine the individual effect of VUV radiation on polymers, and as part of larger test programs where VUV exposure is used in sequential radiation exposure tests. This paper will describe how VUV radiation can affect the properties of polymer films, and the practices used by NASA Glenn Research Center for conducting longduration VUV radiation durability testing.

\section{VUV Effects on Polymers}

The extraterrestrial solar spectrum contains ultraviolet (UV) radiation of wavelengths extending down to the Lyman-alpha emissions of hydrogen at $121 \mathrm{~nm}^{6}$ The high-energy portion of the ultraviolet spectrum containing wavelengths below approximately $200 \mathrm{~nm}$ is generally referred to as vacuum ultraviolet (VUV) radiation. Polymer surfaces on spacecraft are particularly vulnerable to degradation due to incident solar radiation which contains short enough wavelengths and thus high enough energies to break bonds in organic molecules. ${ }^{7}$ Evidence of degradation and embrittlement of Teflon FEP has been observed both in the space environment, ${ }^{8,9}$ and in the laboratory. ${ }^{8,}$ The measured thickness of embrittlement in Teflon FEP was $1 \mu \mathrm{m}$ for material exposed to the space environment on the wake side of the Long Duration Exposure Facility (LDEF) spacecraft where atomic oxygen was negligible. Exposure of Teflon FEP in the laboratory to $124 \mathrm{~nm}$-VUV radiation of approximately 8800 equivalent sun hours (ESH) resulted in formation of an embrittled layer similar to that observed on the LDEF. ${ }^{8}$ Another observation indicated that space-induced embrittlement and laboratory VUV-induced embrittlement can be as deep as $20 \mu \mathrm{m}$ for Teflon FEP. ${ }^{9}$ Laboratory exposures of polyimides of 12.5-25 $\mu \mathrm{m}$ thickness to only approximately 1000 equivalent sun hours of VUV radiation have been observed to cause decreases in spectral reflectance in the ultraviolet to visible wavelength region. ${ }^{11}$ Based on the correlation between space environment-induced polymer properties degradation and similar effects observed upon VUV exposure in the laboratory, it is apparent that VUV testing is an important part of assessing in-space performance for polymer materials.

As a pre-requisite to damaging a polymer material, radiation must be absorbed by or deposited into the polymer. ${ }^{12}$ Therefore, in order to simulate effects of the space radiation environment on polymers, it is important to know the wavelengths or energies that are absorbed or deposited, and the depth of penetration of the radiation being absorbed. In the VUV wavelength region, absorption measurements on Teflon polytetrafluoroethylene (PTFE), very closely related chemically to Teflon FEP, have indicated a strongly absorbing peak centered at approximately $160 \mathrm{~nm}$ wavelength, with a weak absorption tail on the higher wavelength side (above approximately $180 \mathrm{~nm}$ ), and a rising continuous absorption on the lower wavelength side (below approximately $130 \mathrm{~nm}){ }^{13}$ Spectral transmittance measurements for various thicknesses of Teflon FEP were measured by the National Institute for Standards and Technology (NIST) and are shown in Figure 1. It is evident from this figure that nearly all of the VUV radiation below $200 \mathrm{~nm}$ is absorbed within a thickness of $127 \mu \mathrm{m}$. Teflon of one tenth this thickness, $12.7 \mu \mathrm{m}$, absorbs nearly all VUV below 


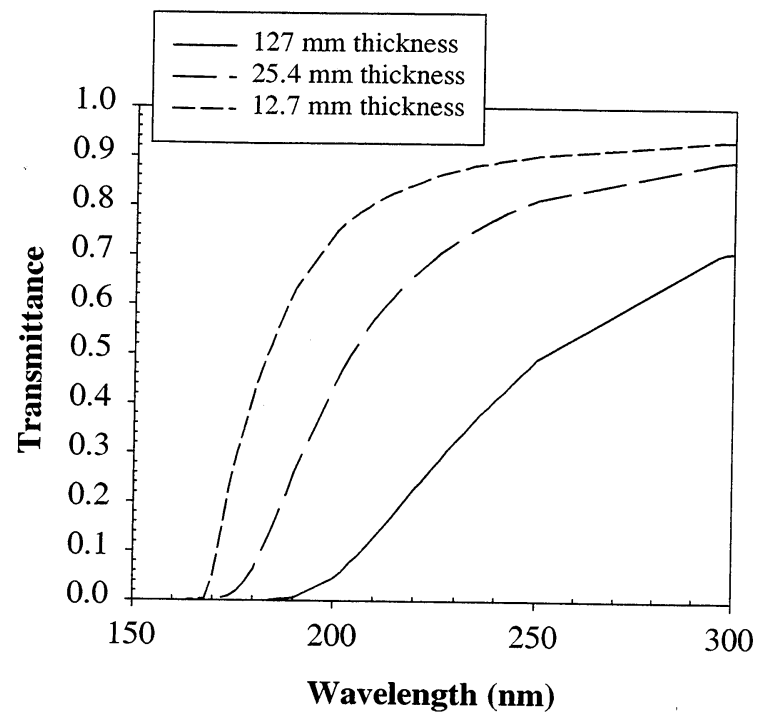

Figure 1: Spectral transmittance of Teflon FEP

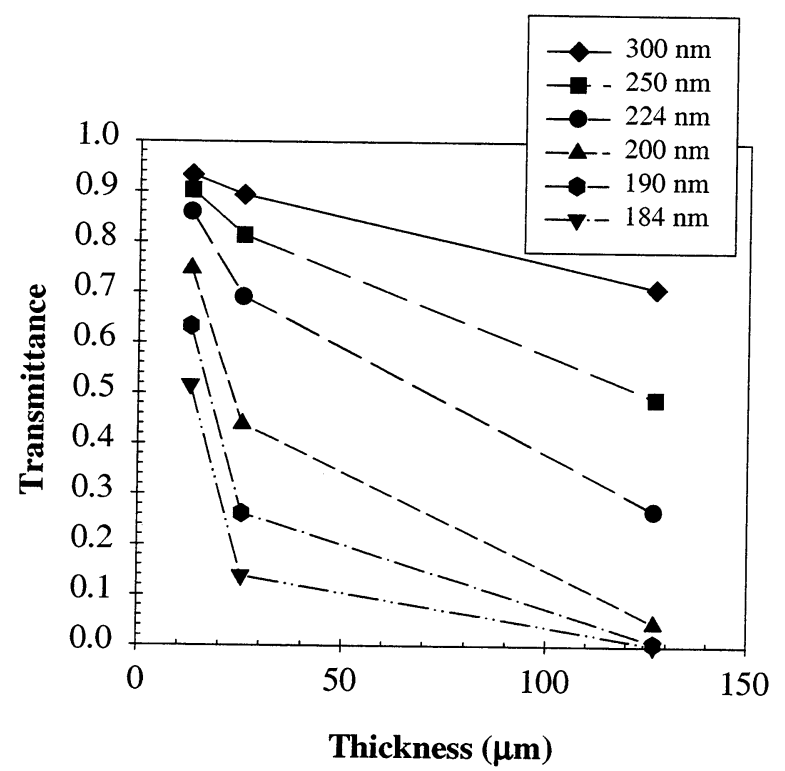

Figure 2: Transmittance as a function of FEP thickness.

$170 \mathrm{~nm}$ wavelength, but is still at least $50 \%$ transmitting down to $180 \mathrm{~nm}$ wavelength. Transmittance as a function of FEP thickness for specific wavelengths is shown in Figure 2.

For wavelengths of $200 \mathrm{~nm}$ and below, there is significantly greater attenuation of the VUV radiation for the same thickness of FEP as compared to longer wavelengths. This means that the shorter wavelength VUV radiation is more absorbed by thin surface layers as compared to longer wavelengths.

It is generally thought that most polymers absorb approximately $95 \%$ of incident radiation below $250 \mathrm{~nm}$ within $0.3 \mu \mathrm{m}$ from the surface. ${ }^{12}$ However, based on the data shown in Figures 1 and 2, Teflon FEP is an exception as it transmits ultraviolet radiation to a much greater depth than $0.3 \mu \mathrm{m}$. On the other hand, polyimides such as Kapton, also commonly used in spacecraft thermal control materials, absorb at least $75 \%$ of photons of $193 \mathrm{~nm}$ wavelength within less than $0.1 \mu \mathrm{m}$ from the surface. ${ }^{12}$

\section{Characterization Of VUV Source}

The VUV exposure facilities at NASA Glenn Research Center use deuterium lamps with magnesium fluoride windows (Hamamatsu model L879-01 and its recent replacement, model L7293) which provide a continuum spectral output between approximately 115 and $400 \mathrm{~nm}$. Calibration of one L879-01 lamp and two Hamamatsu L7293 lamps has been conducted by NIST. Irradiance, known as the radiant energy incident on a surface per unit time per area per bandwidth $\left(\mathrm{J} / \mathrm{cm}^{2} / \mathrm{nm} / \mathrm{s}\right.$ or $\left.W / \mathrm{cm}^{2} / \mathrm{nm}\right)$, was measured using a detector with a circular area $6 \mathrm{~mm}$ in diameter. Sources were operated in a container purged with argon at atmospheric pressure. Argon will not absorb VUV wavelengths. For each peak wavelength at which data were obtained, the bandwidth over which radiation was detected was approximately $1.6 \mathrm{~nm}$. The irradiance spectra for these lamps measured using a $25.4 \mathrm{~cm}$ distance from the source to the detector are shown in Figure 3 as compared to the air mass zero (AMO) solar spectral irradiance. ${ }^{14}$ As shown in Figure 3, these lamps can provide many times the sun's irradiance for wavelengths of $160 \mathrm{~nm}$ and below, and, therefore, they can facilitate accelerated testing. However, at wavelengths above approximately $160 \mathrm{~nm}$, the deuterium lamp spectrum shows a decreased radiation output with increasing wavelength, whereas AMO solar irradiance continues to increase with increasing wavelength. Despite the fact that the spectral shape of the lamp does not match that of the sun, the benefit of this lamp over single-wavelength VUV sources is the broad spectral output. Because wavelength dependence of VUV damage to polymers is not well known, it is important that the full spectrum be represented during testing. 
NIST also obtained irradiance at $270 \mathrm{~nm}$ as a function of source-to-detector distance for two L7293 deuterium lamps as shown in Figure 4. The source-to-detector distance is defined as the distance between the center of the lamp body where discharge is initiated and the detector surface.

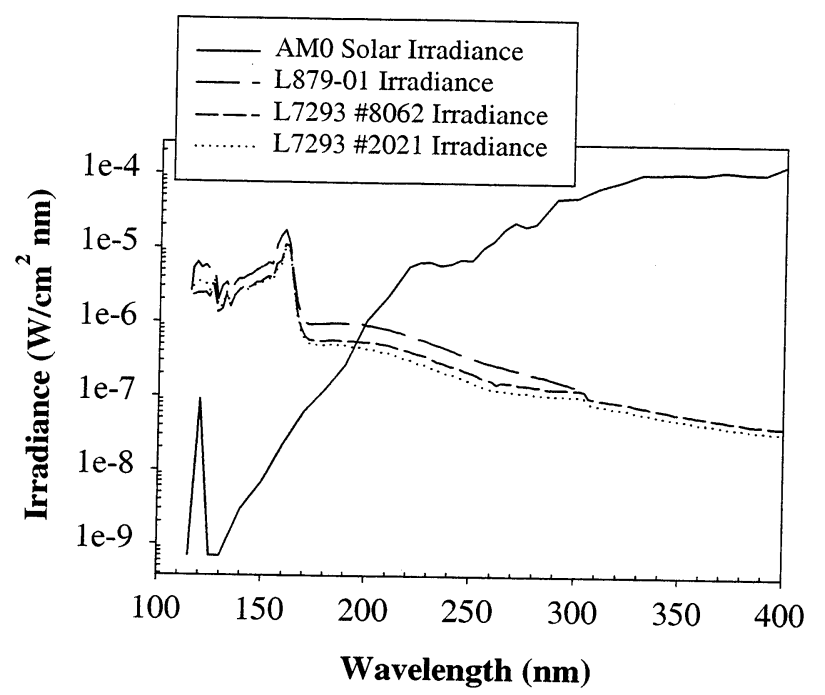

Figure 3: Deuterium lamp and solar air mass zero (AM0) spectral irradiance

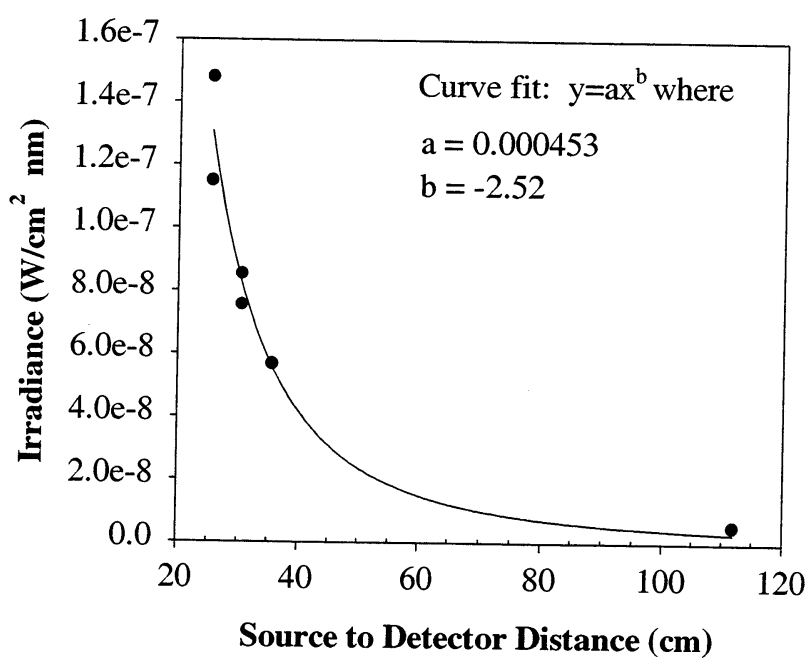

Figure 4: Irradiance as a function of on-axis distance between the VUV source and detector.

Because the lamps have a projecting tube of approximately $5 \mathrm{~cm}$ length and $1.5 \mathrm{~cm}$ diameter extending from the lamp body, and the VUV transmitting magnesium fluoride window is located at the end of the projecting tube, these lamps do not function as point sources. As shown in the equation in Figure 4, the lamp output follows a function of $1 /(\text { dist })^{2.5}$ for the distances measured.

It is also important to know the variation of the lamp irradiance over a desired exposure area to determine useable sample area. Irradiance as a function of distance across the illumination area is given for an L879-01 lamp in Figure $5 \mathrm{a}$ and $5 \mathrm{~b}$ for four on-axis source-to-detector distances.

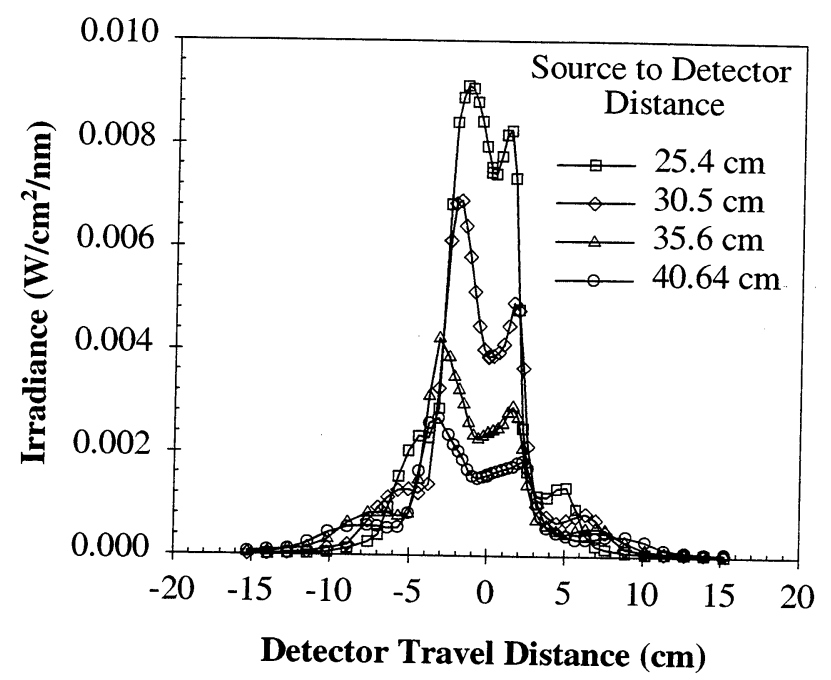

(a)

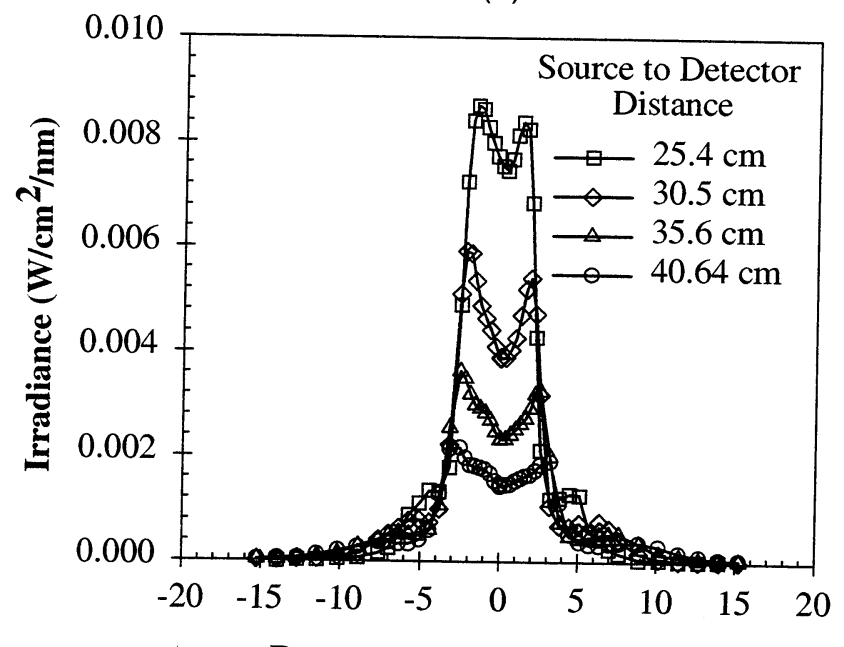

Detector Travel Distance (cm)

(b)

Figure 5: Irradiance of deuterium lamp at $182 \mathrm{~nm}$ across illumination area at various on-axis source to detector distances for direction of detector travel (a) parallel to lamp-body axis and (b) perpendicular to lamp-body axis.

These data were measured in air using a VUV sensitive photomultiplier tube (PMT) and a narrow bandpass filter with a peak wavelength of $182 \mathrm{~nm}$ and a detector area of approximately $19 \mathrm{~mm}$ wide 
by $17 \mathrm{~mm}$ high. As shown in Figures $5 a$ and $5 b$, the lamps produce two peaks of irrad ance across the detector travel distance. For a given on-axis source-to-detector distance, the distance between the two peak irradiance values was averaged for the case of detector travel parallel and perpendicular to the lamp-body axis to define the diameter of illumination. The diameter of illumination as a function on on-axis source to detector distance is shown in Figure 6. The data indicate that at a distance of $25.4 \mathrm{~cm}$ from source (center of lamp body) to sample surface, the useable exposure diameter is approximately $3.25 \mathrm{~cm}$, whereas at a distance of $40.6 \mathrm{~cm}$, the useable exposure diameter increases to $5.8 \mathrm{~cm}$.

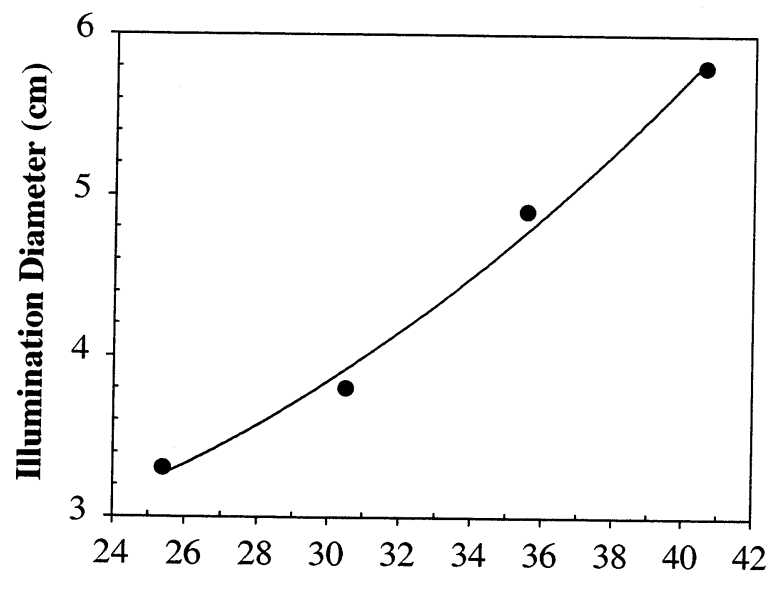

Source-to-Sample Distance $(\mathrm{cm})$

Figure 6: VUV illumination diameter as a function of distance between the source and sample plane.

\section{Methods And Considerations For VUV Exposure Testing}

Deuterium lamps used for VUV exposure of materials at GRC are calibrated with cesium iodide (Csl) phototubes with magnesium fluoride windows which are sensitive over the wavelength range of 115-200 nm (Hamamatsu Model R1187), where the deuterium lamps have their most significant output. The phototubes themselves are first calibrated in the GRC facility by measuring the signal (in amps) from a NIST-calibrated deuterium lamp with a magnesium fluoride window measured at the same distance. The spectral irradiance curve for the NIST-calibration data is integrated in the sensitive wavelength range of the detector, $115-200 \mathrm{~nm}$, to obtain intensity, or $W / \mathrm{cm}^{2}$ in that wavelength range. Then the intensity/signal ratio (in units of $W / \mathrm{cm}^{2} / A$ ) for that detector can be multiplied by lamp signal (in A) from any "unknown" lamp to obtain 115-200 nm intensity (in $\mathrm{W} / \mathrm{cm}^{2}$ ) for that lamp. Because degradation is not usually known as a function of intensity, VUV intensities for polymer exposures are typically limited to no more than 3-5 times that of the sun in the 115-200 nm wavelength range. Also, because output varies from lamp to lamp, the source-tosample distance to achieve the desired intensity will vary, thus necessitating calibration of each lamp used.

It is important to know how much degradation in lamp output occurs as a function of operating time in a test facility. Contaminants in a vacuum system can build up or "fix" on the lamp's magnesium fluoride windows significantly decreasing the lamp output over time. Use of deuterium lamps with an oil diffusion-pumped vacuum system without a cryogenic trap produced greater than one percent decrease per hour in the VUV transmittance of magnesium fluoride windows. Replacing the diffusion pump with a cryogenic pump has reduced the lamp output degradation in this facility by approximately fifty percent. Recent testing at NASA GRC has shown degradation in the measured 115-200 nm VUV intensity of $0.7 \%$ per hour. Cleaning the lamps' magnesium fluoride windows with 6 micrometer particle size diamond polishing compound (Metadi from Buehler Inc.) followed by an alcohol rinse and drying with nitrogen gas was found to restore the lamp VUV output to near-new values. This procedure has been used for VUV lamp maintenance approximately every 100 operating hours.

When VUV deuterium lamps were used in conjunction with atomic oxygen exposure, VUV output was well-maintained as the atomic oxygen removed organic contaminants before they built up on the lamp window. In one case, a lamp used for over 500 hours along with atomic oxygen showed a decrease in VUV output of less than $10 \%$.

Although the deuterium lamps are intended to provide radiation which cannot be transmitted in air, their lifetime is short when operated fully inside of a vacuum chamber. A set of 16 deuterium lamps was found to have an average life of no more than 75 hours when operated with the lamp fully inside of a vacuum chamber, although the reasons for early failure were not able to be conclusively determined. Alternative to locating the whole lamp in vacuum, the long projectiontube can be pushed through an o-ring compression fitting allowing the body of the lamp 
to be outside of vacuum with just the projectiontube inside the vacuum chamber. Lamps used in this way have remained functional for at least several hundred operating hours.

Modifications to the VUV exposure facility at NASA GRC have incorporated many of these lessons-learned in order to maximize exposure time and minimize maintenance down-time. The facility is a cryopumped vacuum chamber which achieves a system pressure of approximately $5 \mathrm{x}$ $10^{-6}$ torr. It contains four individual VUV exposure compartments in vacuum separated by watercooled copper walls to minimize VUV radiation and any sample contamination cross interactions between compartments. Each VUV exposure compartment contains a VUV deuterium lamp with a magnesium fluoride window, a motor-controlled sample stage coupled with a moveable CsI VUV phototube, and two thermocouples for temperature measurement. Figure $7 \mathrm{a}$ shows the vacuum chamber and exterior equipment. As shown in the figure, each VUV lamp is located at the top of the chamber with its projection-tube pushed through an o-ring compression fitting. The lamp assemblies are located on ports which can be isolated from the rest of the vacuum chamber permitting maintenance or replacement of the lamps without breaking vacuum in the main chamber where the samples are located. Figure $7 \mathrm{~b}$ shows a view of two of the four interior VUV exposure compartments including the moveable sample stages and detector holders. When the motor moves the sample holder/detector assembly in the upward direction, the detector "arm" is rotated to stow the detector under a shield blocking VUV exposure of the detector. This is the sample exposure configuration. When the sample stage/detector assembly is moved downward, the detector is rotated and repositioned over the samples. This is the VUV lamp calibration configuration. The moveable sample stage/detector assembly facilitates repositioning of samples closer to the VUV lamps as the lamp output degrades over time, thus maintaining desired VUV intensity over time. When the sample stage reaches the top limit of its position, further degradation in VUV intensity below the desired level requires interruption of the VUV exposure for lamp maintenance. Computer control of this facility provides for 24-hour operation, automated lamp calibration and sample position adjustment, and data acquisition for VUV lamp intensity and sample temperature over the course of the VUV exposure time. Further details

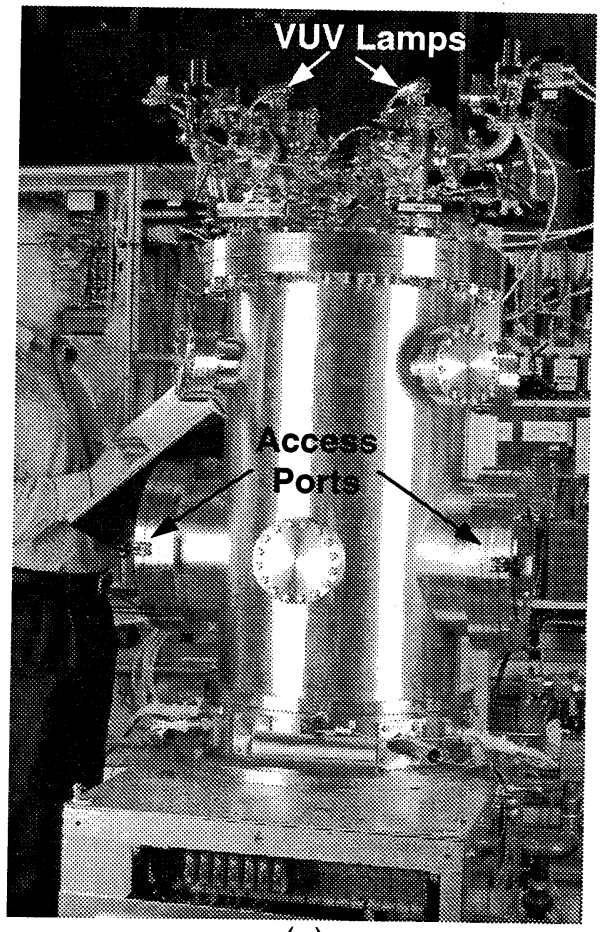

(a)

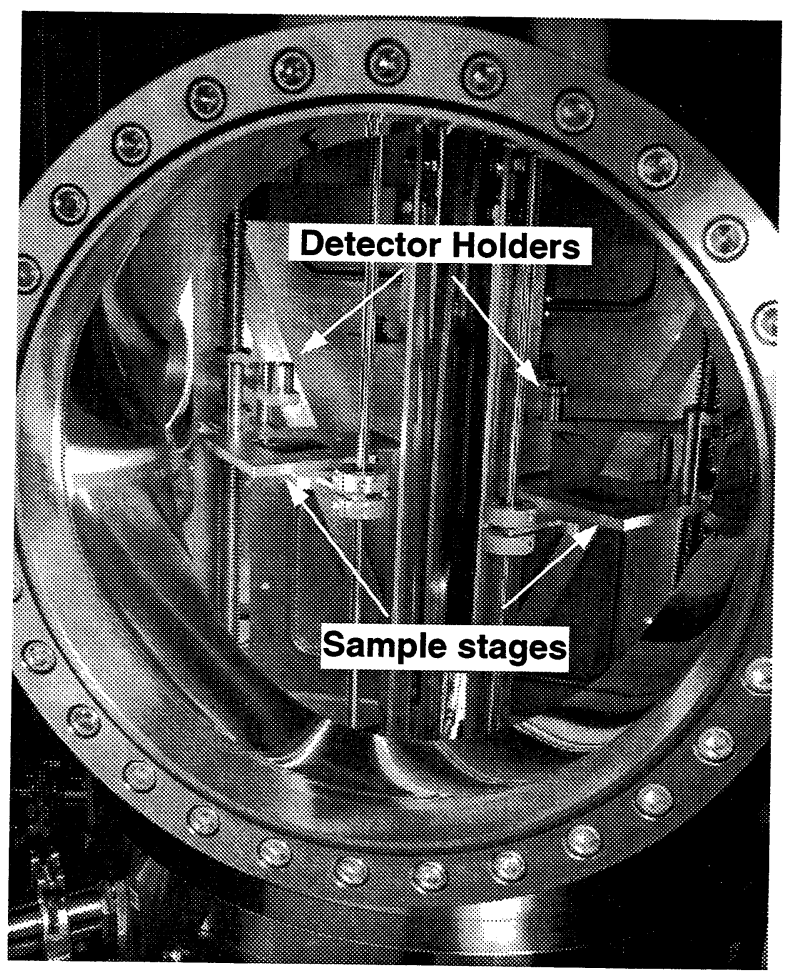

(b)

Figure 7: NASA GRC VUV exposure facility

(a) overview showing exterior components, and

(b) view of two of the four VUV exposure

compartments through access port window. 
on the design and features of this facility are given in Reference 15.

\section{Summary}

Because of the significant effect that VUV radiation can cause in the mechanical, chemical, and optical properties of polymer materials, it is important that VUV radiation exposure testing be part of comprehensive test programs determining overall space environmental effects on polymer surfaces. Because the wavelength sensitivity of VUV damage is not well known, using a broadspectrum VUV source such as a deuterium lamp with a magnesium fluoride window can assure that the damaging VUV wavelengths are present during exposure. Characterization of deuterium lamps has been obtained through the National Institute of Standards and Technology and through measurements at NASA GRC. Spectral irradiance measurements show that from approximately 115 to $160 \mathrm{~nm}$, deuterium lamp irradiance can be many times that of air mass zero solar irradiance, and as wavelength increases above approximately $160 \mathrm{~nm}$, deuterium lamp irradiance decreases in comparison to the sun. Because the deuterium lamps used contain a projection-tube, they do not function as point sources. Irradiance rather follows a function of $1 /(\text { dist })^{2.5}$. The useable illumination area for these lamps is limited by the size of the projection-tube's magnesium fluoride end-window, the only area through which VUV radiation is transmitted. Vacuum system contamination can cause significant degradation in lamp output over time, but the magnesium fluoride end-windows can be cleaned to restore output. Oil-free pumping systems are recommended to reduce the rate of lamp output degradation. Lamp lifetime is significantly reduced when lamps are installed inside vacuum systems. When lamps are operated with their projection-tubes pushed through o-ring compression fittings, useful lifetime is substantially increased. NASA GRC has re-designed their VUV exposure facility to incorporate lessons-learned and to maximize VUV exposure time by minimizing maintenance downtime.

\section{$\underline{\text { References }}$}

1. Hall, D. F., Fote, A. A., "10 Year Performance of Thermal Control Coatings at Geosynchronous Altitude," AIAA-91-1325, June 1991.
2. Townsend, J. A., Hansen, P. A., McClendon, M. W., de Groh, K. K., Banks, B. A., "Hubble Space Telescope metallized Teflon FEP thermal control materials: on-orbit degradation and post-retrieval analysis," High Performance Polymers, Vol. 11, No. 1, March 1999.

3. Perrygo, C., Choi, M., Parrish, K., Schunk, G., Stanley, D., Wooldridge, E., "Passive thermal control of the NGST," SPIE 3356-66, 1998.

4. Dever, J., A., de Groh, K. K., Banks, B. A., Townsend, J. A., Barth, J. L., Thomson, S., Gregory, T., Savage, W., "Environmental Exposure Conditions for Teflon Fluorinated Ethylene Propylene on the Hubble Space Telescope," High Performance Polymers, Vol. 12, No. 1, March 2000.

5. Adams, M. R., "The Degradation of Polymeric Spacecraft Materials by Far-UV Radiation and Atomic Oxygen," UMI Dissertation Services, Ann Arbor, MI, 1993, p. 9.

6. Forsythe, J. S., George, G. A., Hill, D. J. T., O'Donnell, J. H., Pomery, P. J., Rasoul, F. A., "The Effect of Simulated Low Earth Orbit Radiation on Polyimides (UV Degradation Study)" in NASA CP3275, LDEF-69 Months in Space - Third Post-Retrieval Symposium, Part 2, November 8-12, 1993, pp. 645-656.

7. Dever, J. A., "Low Earth Orbital Atomic Oxygen and Ultraviolet Radiation Effects on Polymers," in Flight-vehicle materials, structures, and dynamics - Assessment and Future Directions, Vol. 2, Advanced Metallics, Metal-Matrix and Polymer-Matrix Composites; New York, NY, American Society of Mechanical Engineers, 1994, p. 422-433; also as NASA TM 103711, February 1991.

8. Brinza, D. E., Stiegman, A. E., Staszak, P. R., Laue, E. G., Liang, R. H., "Vacuum Ultraviolet (VUV) Radiation - Induced Degradation of Fluorinated Ethylene Propylene (FEP) Teflon Aboard The Long Duration Exposure Facility (LDEF)," in LDEF-69 Months in Space - First Post-Retrieval Symposium, Part 2, June 1991, pp. 817-829.

9. Skurat, V. E., Barbashev, E. A., Budashov, I. A., Dorofeev, Y. I., Nikiforov, A. P., Ternovoy, A. I., Van Eesbeek, M., Levadou, F., "The Separate and Combined Effects of VUV Radiation and Fast Atomic Oxygen on Teflon FEP and Silicon Carbide," in Proceedings of the $7^{\text {th }}$ International Symposium on Material in Space Environment, June 16-20, 1997, Noordwijk, Netherlands, ESA, 1997, pp. 267279. 
10. Grossman, E., Noter, Y., Lifshitz, Y., "Oxygen and VUV Irradiation of Polymers: Atomic Force Microscopy (AFM) and Complementary Studies," in Proceedings of the $7^{\text {th }}$ International Symposium on Material in Space Environment, June 16-20, 1997, Noordwijk, Netherlands, ESA, 1997, pp. 217-223.

11. Dever, J., Messer, R., Powers, C., Townsend, J., Wooldridge, E., "Effects of Vacuum Ultraviolet Radiation on Thin Polyimide Films," in Proceedings of the $8^{\text {th }}$ International Symposium on Materials in a Space Environment $/ 5^{\text {th }}$ International Conference on Protection of Materials and Structures from the LEO Space Environment, Centre National D'etudes Spatiales, June 2000.

12. Adams, M. R., "The Degradation of Polymeric Spacecraft Materials by Far-UV Radiation and
Atomic Oxygen," UMI Dissertation Services, Ann Arbor, MI, 1993, p. 138.

13. Seki, K., Tanaka, H., Ohta, T., "Electronic Structure of Poly(tetrafluoroethylene) Studied by UPS, VUV Absorption, and Band Calculations," Physica Scripta, Vol. 41, pp. 167-171, 1990.

14. American Society for Testing and Materials ASTM-E 490-73a (Reapproved 1992), "Solar Constant and Air Mass Zero Solar Spectral Irradiance Tables."

15. Stueber, T. J., Sechkar, E. A., Dever, J. A., Banks, B., A., "Steady State Vacuum Ultraviolet Exposure Facility with Automated Calibration Capability," NASATTM-2000210053, May 2000. 

1. AGENCY USE ONLY (Leave blank) 2 2. REPORT DATE

4. TITLE AND SUBTITLE

January 2002

Technical Memorandum

\section{Simulated Space Vacuum Ultraviolet (VUV) Exposure Testing for Polymer Films}

6. AUTHOR(S)

WU-755-1A-13-00

Joyce A. Dever, Anthony J. Pietromica, Thomas J. Stueber,

Edward A. Sechkar, and Russell K. Messer

7. PERFORMING ORGANIZATION NAME(S) AND ADDRESS(ES)

National Aeronautics and Space Administration

John H. Glenn Research Center at Lewis Field

Cleveland, Ohio 44135-3191

8. PERFORMING ORGANIZATION REPORT NUMBER

E-13148

\section{SPONSORING/MONITORING AGENCY NAME(S) AND ADDRESS(ES)}

National Aeronautics and Space Administration

Washington, DC 20546-0001

10. SPONSORING/MONITORING AGENCY REPORT NUMBER

NASA TM-2002-211337

AIAA-2001-1054

\section{SUPPLEMENTARY NOTES}

Prepared for the 39th Aerospace Sciences Meeting and Exhibit sponsored by the American Institute of Aeronautics and Astronautics, Reno, Nevada, January 8-11, 2001. Joyce A. Dever, NASA Glenn Research Center; Anthony J. Pietromica, Ohio Aerospace Institute, 22800 Cedar Point Road, Brook Park, Ohio 44142; Thomas J. Stueber and Edward A. Sechkar, Dynacs Engineering Company, Inc., 21000 Brookpark Road, Cleveland, Ohio 44135; and Russell K. Messer, Cleveland State University, Cleveland, Ohio 44115.

Responsible person, Joyce A. Dever, organization code 5480, 216-433-6294.

12a. DISTRIBUTION/AVAILABILITY STATEMENT

Unclassified - Unlimited

Subject Category: 18

Distribution: Nonstandard

Available electronically at http://gltrs.grc.nasa.gov/GLTRS

This publication is available from the NASA Center for AeroSpace Information, 301-621-0390.

13. ABSTRACT (Maximum 200 words)

Vacuum ultraviolet (VUV) radiation of wavelengths between 115 and $200 \mathrm{~nm}$ produced by the sun in the space environment can cause degradation to polymer films producing changes in optical, mechanical, and chemical properties. These effects are particularly important for thin polymer films being considered for ultra-lightweight space structures, because, for most polymers, VUV radiation is absorbed in a thin surface layer. NASA Glenn Research Center has developed facilities and methods for long-term ground testing of polymer films to evaluate space environmental VUV radiation effects. VUV exposure can also be used as part of sequential simulated space environmental exposures to determine combined damaging effects. This paper will describe the effects of VUV on polymer films and the necessity for ground testing. Testing practices used at Glenn Research Center for VUV exposure testing will be described including characterization of the VUV radiation source used, calibration procedures traceable to the National Institute of Standards and Technology (NIST), and testing techniques for VUV exposure of polymer surfaces.

\section{SUBJECT TERMS}

Far ultraviolet radiation; Space environmental simulation; Polymers 14

\begin{tabular}{|c|c|}
\hline $\begin{array}{c}\text { 17. SECURITY CLASSIFICATION } \\
\text { OF REPORT }\end{array}$ & $\begin{array}{c}\text { 18. SECURITY CLASSIFICATION } \\
\text { OF THIS PAGE } \\
\text { Unclassified }\end{array}$ \\
Unclassified
\end{tabular}

19. SECURITY CLASSIFICATION OF ABSTRACT Unclassified 